\title{
Transmedia Storytelling and Cultural Heritage Tourism
}

Nicole Basaraba*

DOI: https://doi.org/10.17230/9789587206289ch1

Owen Conlan**

Jennifer Edmond $d^{* * *}$

Peter Arnds****

\section{Introduction}

Transmedia stories, largely situated in genre fiction, provide interconnected narratives rooted in one story on multiple digital and non-digital platforms (McNely \& Teston, 2015) and have enough added value to be worth seeking out and consuming (Perryman, 2008, p. 33). Transmedia provides a strong foundation for adopting new methods of digital storytelling because it incorporates elements from both narrative and gaming into a "ludonarrative construct" (Aarseth, 2012), which is immersive, pleasurable, and participatory for the audience. Transmedia is immersive because people are motivated to seek out and follow the narrative across different media and they "develop the skills to deal with the flow of stories and become hunters of information from multiple sources" (Scolari, 2009, p. 589). Each piece of a transmedia narrative functions as, what Ryan (2015) calls, a micronarrative (small piece) that is part of a larger macro-narrative (full story). Each micro-narrative in a transmedia story can be understood on its own, but it also adds value to the whole macro-narrative system. Transmedia is

" Master of Arts in Communications and Technology, University of Alberta; Ph.D. Candidate ADAPT: Global Centre of Excellence for Digital Content Technologies, Trinity College Dublin, Ireland. Email: nicole.basaraba@adaptcentre.ie

** Ph.D. Computer Science, Trinity College. Associate Professor of Computer Science, ADAPT Theme Leader: Personalising the User Experience, Theme Leader for Digital Humanities at Trinity College Dublin. Email: owen.conlan@scss.tcd.ie

*** Bachelor of Arts in German Literature, Boston University; Ph.D. in Germanic Languages and Literatures, Yale University. Director of Strategic Projects, Faculty of Arts Humanities and Social Sciences Research Fellow, Theme Leader for Digital Humanities at Trinity College Dublin. Email: jennifer.edmond@tcd.ie

${ }^{* * * *}$ Master of Arts in English Language and Literature, Ludwig-Maximilians Universität München; Ph.D. in German Studies, University of Toronto. Associate Professor, Director of Comparative Literature MPhil, Head of Italian Department, Trinity College Dublin. Email:arndsp@tcd.ie 
also participatory/interactive because the audience experiences pleasure from collecting and piecing together the different narratives.

Figure 1 : Transmedia storytelling visualised

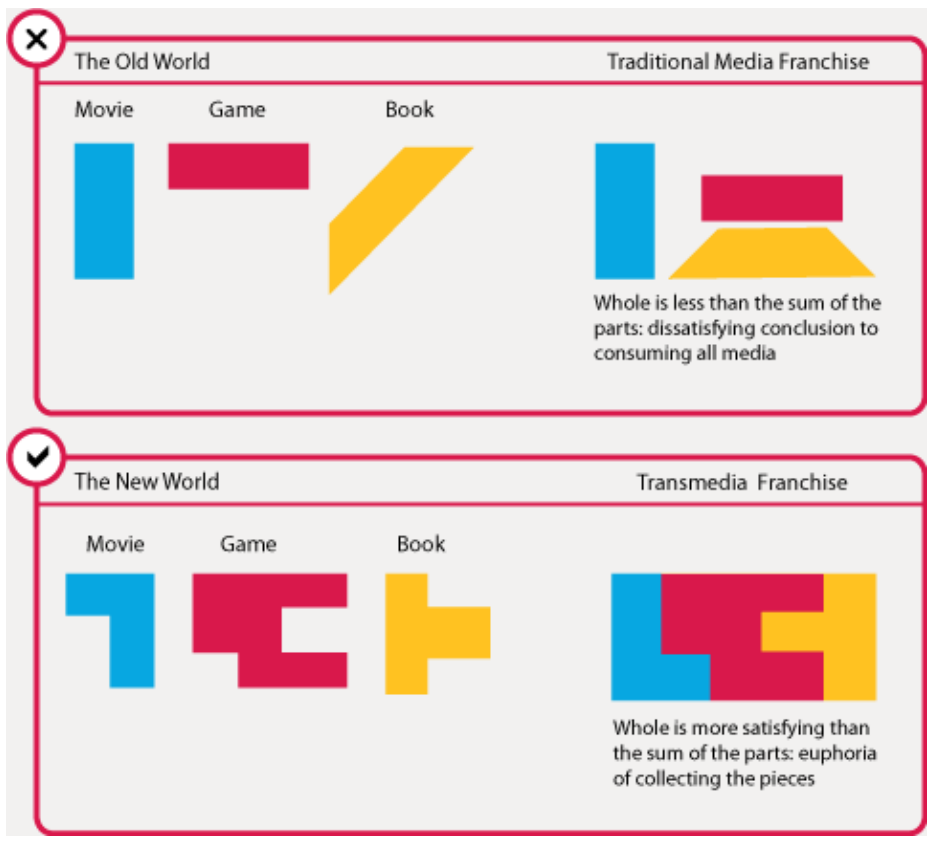

Source: Pratten (2011, p. 2).

Transmedia stories, depending on the formats, can fall under the umbrella description of Interactive Digital Narratives (IDNS). IDNS are described as "a form of digital interactive experience in which users create or influence a dramatic storyline through actions, either by assuming the role of a character in a fictional virtual world, issuing commands to computercontrolled characters, or directly manipulating the fictional world state" (Riedl \& Bulitko, 2013, p. 67). The IDN format challenges the role of the author and the fixed state of content and structure because the audience takes on an active role and the narratives become malleable (Koenitz, Haahr, Ferri, \& Sezen, 2013). A primary difference between transmedia stories and IDNS is that, in the latter, the interactors have agency, which Murray (1997) describes as "the satisfying power to take meaningful action and see the results of our decisions and choices" (1997, p. 126). While in the IDN format, the interactors create their own personalised 
narrative path, in a transmedia, the stories are authored across platforms. Although there is user interaction, the audience often does not have the agency to change the direction or outcome of the story, being video games an exception. Even the term 'audience', used in transmedia, versus 'users' or 'interactors', as IDN consumers are commonly referred to, highlights the difference between the more passive and active roles, respectively. To date, IDNS have largely been developed and studied as fiction-based video games, such as Facade, IDTension, and Half Life 2 (Koenitz et al., 2013, pp. 29-30). However, IDNS are beginning to appear in non-fiction applications such as education and training (Riedl \& Bulitko, 2013, p. 67).

Video games, with their high-level of interactivity, have steered a scholarly debate between narratologists (i.e., narrative studies) and emergent game studies (i.e., ludology) on whether video games actually contain narrative or narrativity (Aarseth, 2012). If narrative demands the receiver to recognize the authorial judgement of the text as a narrative, narrativity considers if the text author intended to do so on a script and whether or not there is an author (e.g., a painting, a song, or websites) (Ryan, n. d.). Some scholars have argued that video games are narratives, while others argue that they contain some narrative, or none. The aim of this work is not to delineate between the corresponding disciplines, but to draw upon the theories and practices from both transmedia storytelling and video games to address the "narrative paradox" or "ludonarrative dissonance". This paradox or dissonance describes the tension between narrative and interactivity, where user interaction disrupts the narrative structure and may lead to confusion (Hargood, Jewel, \& Millard, 2012, p. 1). Finding the balance between a narrative structure, while allowing user interaction, is a challenge that will be addressed in the context of creating interactive digital narratives (IDN) for cultural heritage tourists.

\section{Background}

Cultural heritage is commonly understood as the tangible (e.g., monuments, groups of buildings, sites), the intangible (e.g., practices, representations, expressions, knowledge, skills), and environments (e.g., archaeological sites) (Ahmad, 2006, p. 298). Many cultural heritage and preservation organisations like museums, libraries, and non-profits recognise the increasing importance of the digital medium and are digitising 
their multimodal ${ }^{1}$ materials (e.g., artefacts, books, photos, records, etc.), creating virtual tours, and personalising exhibitions for the public to see and experience histories and culture (Ardissono, Kuflik, \& Petrelli, 2012). European scholars have recently become more engaged in "public history" research which focuses on non-academic audiences by finding present-day history applications, and developing collaborative practices (Cauvin \& O'Neill, 2017, p. 2). Because cultural heritage is constructed by a community, there is not a single story; also, sharing memory through storytelling helps to provide a sense of identity and unifies people (Walker, 2010). People create narratives associated with places, monuments, events, and this contributes to collective memory making, following Walker's theories (2010). On the other hand, Ryan says that the stories of a life or community are not only one epic narrative, but are made up of smaller episodes that can be read in different orders, and he suggests that projects that explore local history, or preserve cultural memory lend themselves well to the non-linear browsing navigation (2002, p. 606) This reinforces the idea of cultural heritage, with its many potential narratives, as a non-fiction application well suited to an IDN format.

Cultural heritage tourists seek local heritage through archaeological sites, historical landscapes, local architecture, museums, art expressions, traditions and practices of the past (Timothy \& Nyaupane, 2009 as cited in Dragouni \& Fouseki, 2017, p. 1). Today's tourists are influenced and informed by many transmedial sources such as books, movies, photos, websites, social media, and word of mouth. Fáilte Ireland's statistics show that $80 \%$ of tourists used the Internet as a primary source for planning their trip, $28 \%$ asked friends/family, $12 \%$ consulted a travel agent, and $23 \%$ used guidebooks (Fáilte Ireland, 2016). Tourists are also participating in co-creation or co-performance of the experience (Stylianou-Lambert, 2011). There are blogs dedicated to different niche travel communities such as solo, female, adventure, sustainable, and quit-work-to-travel, to fill the gaps of the personalised content they seek. This information is spread across many different sources, both online and on physical locations. So, the curious explorers are required to find their contents of interest and sew them together to gain a cohesive understanding of the place they want to visit, which is a similar practice for transmedia stories seekers.

1 Multimodality can be defined as "the simultaneous co-deployment of resources within a single communication process for meaning-making purposes" (Francesconi, 2014, p. 129). 
Cultural heritage digital narratives are found in various media such as locative media games, ${ }^{2}$ websites, videos, and exhibitions. Examples of scholar-led works include: The Voices of Oakland Cemetery, a mini-computer that provides auditory content to introduce virtual or in-person visitors to the history, architecture, and dramatised personal stories of notable people buried in that cemetery from the United States (Voices of Oakland, 2017); the mARCHive, a 360-degree video exhibition of the archives from Museums Victoria in Australia (Kenderdine \& Hart, 2014); and "London: A City Through Time" iPad app with multimodal historical content about that city in the United Kingdom (HeuristicMedia, 2012). In the current landscape, many digital cultural narratives are scholar-driven and externally funded, with the focus of bringing cultural heritage into a digital space to engage the public. The end products are commonly a database-like website displaying thousands of searchable artefacts now accessible to the public, which brings the challenge that many become "ghost" or "dead websites" (Grabowska, 2017) because they are frequently accessed upon the post-publicity launch and then there is little reason for users to revisit.

Other common digital applications for cultural heritage are technology-enhanced museum experiences (e.g., audio guides and digital visualisations). While these applications improve visitor engagement, they often -for many reasons (e.g., limited source information, issues of copyright, lack of resources)- remediate a small amount of narrative content in different formats through printed placards, brochures and audio guides. Institutions and creative storytellers are experimenting with the digital medium and cultural heritage content, but the creators tend to be top-down focused and often do not conduct follow-up studies to evaluate the user experience in terms of content comprehension, the level of immersion, and satisfaction. Warwick (2012) says that user testing, in both academia and industry, is often left until too late in the project, and users are asked for input after the product has been built and when the prototype is being tested (p. 4). As a result of the digital era, the number of dispersed authoritative and user-generated

Locative media is a "mobile media movement in which location and time are considered essential to the work" (Tuers as cited in Nisi, Oakley, \& Haahr, 2008, p. 72), and require the user to physically move to progress in the game. 
cultural heritage content has increased. Since public history projects are a growing field, there is a need to theoretically and empirically investigate how to create more cohesive digital narratives for cultural heritage, and the hypothesis is that IDNS are a potential solution to face the challenges related to storytelling cultural heritage.

The well-established practices of transmedia storytelling and video game design can support the creation of an IDN system for cultural tourists. In addition to media convergence in an IDN platform, digital technology can also enhance the cultural tourists' experiences by providing missing narratives at physical sites, even in the form of historical visualisations and 3D reconstructions of ancient ruins, for example. The main question this article explores is: How can media convergence practices be used to create personalised experiences for cultural heritage tourists using transmedia stories through an IDN?

\section{Proposed Theoretical Framework}

The successful practices of transmedia storytelling can be applied to specific IDNS theoretical frameworks in non-fiction genres. Koenitz (2010) proposed a theory of IDN involving three main elements: system, process, and product. He explains that an IDN is an expressive digital narrative form fulfilled within a system that contains potential narratives, and is experienced through a process that results in products that are also different narratives (2010, p. 108). While Koenitz outlines these three key components, he does not provide a detailed methodology on how to apply them when creating an IDN, and his work mainly relies on fiction-based video games. This article focuses on cultural heritage narratives, which are a non-fiction genre, and thus moves towards expanding Koenitz's IDN theory to create a framework that practitioners could apply in non-fiction contexts. It is hypothesized that:

1. rhetorical ${ }^{3}$ and narratological theories ${ }^{4}$ can be used as guidelines for creating a system;

3 Rhetoric is defined by Aristotle as "the art (techne) of finding out the available means of persuasion" (as cited by Eyman, 2014, chapter 2, § 14).

4 Narratology is "a humanities discipline dedicated to the study of the logic, principles, and practices of narrative representation" (Meister, 2013). 
2. new media theory/multimodality ${ }^{5}$ used in current digital storytelling practices (e.g., transmedia, and video games), and user-centred ${ }^{6}$ design can improve the process; and

3. personalisation ${ }^{7}$ through user modelling and adaptive hypermedia can create the unique products or emergent narratives -a term used in computer game studies to describe a desirable effect of interactive media that addresses the narrative paradox by reconciling the conflicting values of narrative satisfaction (cohesiveness) and player autonomy (Walsh, 2011, p. 72).

The following sections will briefly outline a proposed theoretical approach towards creating IDNS for cultural tourists.

\section{Designing the System as a Digital Space}

This first part of IDN theory focuses on what goes into a system and the way it is created. Koenitz describes a system as "the digital artefact, as it exists on a digital storage medium, combined with the hardware on which the artefact is executed" (2010, p. 128). The system contains the "potential narratives" or protostories to be explored (Koenitz, 2010, p. 128). We propose that the content of protostories can be determined with the aid of rhetorical theory and that the structure can be supported by narratology. Porter and Sullivan (1994) argue that rhetoric is an applied art and that rhetorical theory acts only as the guiding principles rather than the rules, where principles are always interpreted and adjusted for situations and rarely survive in pure form (as cited by Eyman, 2015, chapter $2, \S 11$ ). While rules are generally in the domain of video games, rhetorical principles may be applied to non-fiction narrative creation. For example, digital rhetoric can be adapted for the construction of an IDN system because it may help answering questions such as: what materials, resources, and information do we have in order to communicate the story?

5 A mode is a single type of semiotic communication such as verbal or visual communication. Multimodality is the presence of many modes in a single medium (such as TV or the Internet).

6 User-centered design, or user experience design, was coined by Don Norman, former VP of the Advanced Technology Group at Apple, to cover all aspects of a personal experience with a system including design, graphics, interface, physical interaction and the manual (Uxdesign, n. d.).

7 Personalisation "attempts to ensure that content and services are tailored to individual users personal preferences, goals, and context” (Lawless, Conlan, \& Hampson, 2016, p. 172). 
Which modes (e.g., text, photos, or video) are these materials in? What methods or situations can we use to persuade the audience to carry out an action and/or gain knowledge and understanding of a culture heritage site?

Once some protostory material has been created, as guided by rhetorical principles, narratology can be used to determine the narrative structure for an IDN system. The linear narrative structure has been used for hundreds of years (e.g., books and movies), but in the digital medium, the possibility for new structures has left the field wide open to experimentation. A possible emergent narrative structure that may be suitable for a cultural heritage IDN is Ryan's Action Space, where "interactivity takes place on the macro-level and the narrative plotting on the microlevel" (Ryan, 2015, p. 174). Since non-fiction does not require a single linear structure with a single plot, the Action Space allows interactors to create a personalised, emergent narrative by navigating through the story path and to make meaningful selections in the different narrative branches. The Action Space differs from a mostly linear narrative structure with some branching, because it functions more like a web with multiple, and possibly an infinite number of, connections. The advantage of the non-fiction genre is that, to make sense, it does not heavily rely on a chronological sequence of events.

\section{The Process of the Interactive Experience}

The process aspect of IDN theory occurs when "a user starts to engage with the system" (Koenitz et al., 2013, p. 129). The process of an IDN system can draw upon transmedia storytelling practices to create more immersive, user-centred, experiences. Pratten (2015) explains,

placing the audience at the centre means fitting experiences around their existing behaviours - their pacing, their location, their personalised content [...]. So if we're going to build responsive environments that wrap the audience in an experience where you can't feel the edges -that's what transmedia storytelling does (as cited in Sánchez-Mesa, Aarseth, Pratten, \& Scolari, 2016, p. 11).

Pratten also identifies a growing drive for non-fiction transmedia since authors, wishing to persuade them, want the audience to connect with the narrative (Sánchez-Mesa et al., 2016). For example, they do not want audiences merely to watch a documentary about refugees, but to 
metaphorically "live the life of a refugee" by putting themselves into the refugees' shoes and to experience the narrative from their own point of view (Pratten, 2015 as cited in Sánchez-Mesa et al., 2016, p. 14). This "lived experience" is a result of immersion, which can help to evoke an emotional response to the narrative. Designing narratives in a way that they immerse the user involves considering which modality is best suited for the type of content to be conveyed.

Transmedial narratology ${ }^{8}$ considers the constraints and affordances associated with a given medium and "disputes the notion that the story level of a narrative [i.e., fabula] remains wholly invariant across shifts in medium" (Herman, 2010, p. 85). Transmedial narratology can be used to address questions such as: "what is the narrative potential of media and of the modalities that they encode; how can the narrative affordances of a given medium be emulated in another medium, what is it that the narratives of a certain medium can do that others cannot?" (Ryan, 2016, p. 2). In other words, in non-fiction IDNS the medium can affect the message being transmitted, so using transmedial narratology to inform the mode choices could enhance immersion in cultural heritage narratives. Immersion can also be enhanced through interface design because it impacts the time someone will spend on a website. If an interface is difficult to navigate, has slow load speeds, or is confusing, a user is likely to leave quicker than if the experience is easy, pleasant, and immersive.

Immersion can also be improved through agency, which offers a different experience than interactivity. Murray (1997) explains that the pleasure of agency in electronic environments is often confused with activity, but activity is not agency (p. 128). In digital environments, agency happens when the actions of users bring tangible results and satisfying user experiences, because they have the power to take meaningful action and see the results of their decisions and choices (Murray, 1997, p. 126). There is an opportunity to personalise cultural heritage narrative experiences by giving agency to the users; video games are part of a genre that tends to offer the most agency to them. However, Murray (1997) identified that spatial navigation through virtual landscapes is one form of digital agency that does not depend on game structure and "can be

8 Transmedial narratology was coined in 2004 by Marie-Laure Ryan to expand the field of narratology to include media other than language, and to initiate a comparative study on the narrative power of different media (Ryan, 2016, p. 2). 
pleasurable in itself, independent of the content of the spaces" (1997, p. 128). Therefore, the user interface would also need to be designed to provide people with the agency to explore an "Action Space" cultural narrative and through this navigation, make meaningful choices that result in an emergent narrative.

\section{The Personalised, Emergent Narrative Product}

The emergent narrative product, or what Koenitz (2010) calls the "instantiated narrative", are different narratives that come from the same source (i.e., system), which are achieved through a participatory process (p. 129). The term emergent narrative communicates the way in which the resulting narrative is born from user interactions, and it is commonly used by other scholars (Louchart \& Aylett, 2004; Swartjes \& Theune, 2006; Conlan et al., 2013; Walsh, 2011; Bertrand \& Haahr, 2015). As the digital medium breaks down the barrier between the author and the reader, there is a greater need to see the user as a participant, rather than just a passive reader. Iser (1989) argues that "a text can only come to life when it is read, and if it is to be examined, it must therefore be studied through the eyes of the reader" $(1989$, p. 4). In IDNS, the narrative comes to life through user interaction and results in different personal narratives, so the next question is: how can creators measure IDN success?

One way to measure success is by determining whether the original rhetorical goal was achieved. In this study, the goal for a cultural heritage IDN is to create an experience that is immersive, offers agency, and results in satisfaction and, ideally, new knowledge. Rhetorical theory can be also applied to evaluate IDNS. For example, Chen (2014) argues that "interactivity presents the essential element of rhetoric: the art of persuasion or convincing; it further epitomizes the three rhetorical elements: ethos, logos, and pathos" (2014, p. 126), which are used in the art of persuasion. Ethos is traditionally referred to the rhetor (i.e., orator), pathos to the emotions elicited through the delivery techniques, and the logos to the logic or arguments. Chen (2014) draws parallels between the concept of ethos and the designer, pathos and the player, and logos and textual, visual, and audible emplotment (p. 130). In the case of IDNS, the ethos would be the negotiation between the primary content creator(s) and the participatory agents, the pathos would be connected to the incorporation of carefully-selected multimodal content to enhance comprehension and immersion, and the 
logos would apply to the system, including structure/navigation, content, and argument/macro-narrative plot. These three aspects of rhetorical persuasion could be used to frame questions for interactors that could be administered in the form of a survey. While the guiding principles are outlined here, a more detailed evaluation framework would be necessary to determine if an IDN successfully communicates a narrative. 


\section{Conclusion}

Transmedia stories are complex, immersive, and participatory, and they take advantage of different media. IDNS provide people with agency to change their individual experience, and they are a new genre of storytelling that currently lacks conventions. As influenced by digital culture, cultural heritage tourists desire individual experiences based on their unique interests, and the hypothesis is that an IDN could create a deeper level of immersion and provide educational content while maintaining a macro-narrative thread. An IDN theoretical framework could provide conventions for creating new products and help expand this newer non-fiction storytelling genre. Rhetorical theory can help focus the narrative before it is created, and can act as a reference point for making further decisions upon building the system. Narratological theory can help to determine the narrative structure and may act as a wireframe, or blueprint, before an IDN is built, and could help to inform how to incorporate different content modalities. Technical and design teams could consider the role of agency and create opportunities for users to make meaningful choices, while interface design may improve immersion so that users do not navigate away from the website. Finally, the IDN can be evaluated in terms of user perception during the co-creation process, between themselves and the creator(s) (ethos); their emotional reaction to immersion during the experience (pathos); what they learned or gained from the narrative; and whether they desire to revisit the narrative in the future (logos). An IDN theoretical framework could lower the need to experiment with the medium, improve the impact of future non-fiction stories, and benefit people who could have a more memorable and affective experience. A cultural heritage IDN system could preserve and uncover local history, lost cultural stories and customs, and allow people to explore and learn about their own and other cultures. 


\section{References}

Aarseth, E. (2012, May). A narrative theory of games. Proceedings of the International Conference on Foundations of Digital Games (FDG'12) (pp. 129133). Raleigh, NG, USA. doi: 10.1145/2282338.2282365

Ahmad, Y. (2006). The scope and definitions of heritage: From tangible and intangible. International Journal of Heritage Studies, 13(3), 292-300. doi: https://doi.org/10.1080/13527250600604639

Ardissono, L., Kuflik, T., \& Petrelli, D. (2011). Personalization in cultural heritage: The road travelled and the one ahead. User Modeling and User-Adapted Interaction, 22(1), 73-99. Available in https://bit.ly/2DaHyQ0 Bertrand, L., \& Haahr, M. (2015). What Makes a Successful Emergent Narrative: The Case of Crusader Kings II. In H. Schoenau-Fog, L. E. Bruni, S. Louchart, \& S. Baceviciute, (Eds.), Interactive Storytelling: 8th International Conference on Interactive Digital Storytelling, ICIDS 2015, Copenhagen, Denmark, November 30-December 4, 2015, proceedings (pp. 259-256). Switzerland: Springer.

Cauvin, T., \& O'Neill, C. (2017). Negotiating public history in the Republic of Ireland: collaborative, applied and usable practices for the profession. Historical Research, 90(249), 1-19. doi: 10.1111/1468-2281.12192 Chen, F. (2014). Toward a Hermeneutic narratology of interactive digital storytelling. In A. Mitchell, C. Fernandez-Vara, \& D. Thue (Eds), Interactive Storytelling: $7^{\text {th }}$ International Conference on Interactive Digital Storytelling, ICIDS 2014, Singapore, November 3-6, 2014 Proceedings (pp. 125-133). Switzerland: Springer.

Conlan, O., Staikopoulos, A., Hampson, C., Lawless, S., \& O’Keeffe, I. (2013). The Narrative Approach to Personalisation. New Review of Hypermedia \& Multimedia, 19(2), 132-157. doi: https://doi.org/10.1080/1 3614568.2013.812150

Dragouni, M., \& Fouseki, K. (2017) Drivers of community participation in heritage tourism planning: an empirical investigation. Journal 
of Heritage Tourism, 13(3), 237-256. doi: https://doi.org/10.1080/174387 3X.2017.1310214

Eyman, D. (2015). Digital rhetoric: Theory, method, practice. [e-book]. Ann Arbour, MI: University of Michigan Press. Retrieved from https://bit. ly/2QD4LTn

Fáilte Ireland. (2016). Tourism Facts 2016 Preliminary. Retrieved from https://bit.ly/2szUFTQ

Francesconi, S. (2014). Reading Tourism Texts: A Multimodal Analysis. Buffalo, NY: Channel View Publications.

Grabowska, K. (2017, May 23). Open Monuments: Can We Make Caring About Heritage Easier? Presentation at Public Humanities Workshop, Trinity College Dublin, Ireland.

Hargood, C., Jewell, M. O., \& Millard, D. E. (2012). The narrative braid: A model for tackling the narrative paradox in adaptive environments. In C. Hargood, \& D. Millard (Eds.), Proceedings of the Second workshop on Narrative and Hypertext at HT' 12, 23 ${ }^{\text {rd }}$ ACM Conference on Hypertext and Social Media, Milwaukee, WI, USA (pp. 13-18). New York, NY: Association for Computing Machinery. Retrieved from https://bit.ly/2SabkJL Herman, D. (2010). Word-image/utterance-gesture: Case studies in multimodal storytelling. In R. Page (Ed.), New Perspectives on Narrative and Multimodality (pp. 78-98). New York, NY: Routledge.

HeuristicMedia. (2012). London: A City Through Time [Video]. Retrieved from https://bit.ly/2BucRDj

Iser, W. (1989). Indeterminacy and the Reader's Response in Prose Fiction. In Prospecting: From Reader Response to Literary Anthropology (pp. 3-30). Baltimore, MD: John Hopkins University Press.

Kenderdine, S., \& Hart, T. (2014). mARChive: Sculpting Museums Victoria's Collections. MW 2014: Museums and the Web 2014. Retrieved from https://bit.ly/2t4lIW1

Koenitz, H. (2010). Reframing interactive digital narrative: Toward an inclusive open-ended iterative process for research and practice (Doctoral dissertation). Georgia Institute of Technology, Atlanta, GA. Retrieved from https://b.gatech.edu/2ScG50A

Koenitz, H., Haahr, M., Ferri, G., \& Sezen, T. I. (2013). First Steps towards a Unified Theory for Interactive Digital Narrative. In Z. Pan, 
A. D. Cheok, W. Muller, I. Iurgel, P. Paolo, \& B. Urban (Eds.), Transactions on Edutainment X (pp. 20-35). Berlin - Heidelberg, Germany: Springer-Verlag.

Lawless, S., Conlan, O., \& Hampson, C. (2016). Tailoring access to content. In S. Schreibman, R. Siemens, \& J. Unsworth (Eds.), A New Companion to Digital Humanities (pp. 171-184). Chichester, West Sussex, England: Wiley Blackwell.

Louchart, S., \& Aylett, R. (2004). Emergent narrative, requirements and high-level architecture. Proceedings of the 3rd Hellenic Conference on Artificial Intelligence (SETN 04) (pp. 298-308). Retrieved from https:// bit.ly/2PKhQVH

McNely, B., \& Teston, C. (2015). Tactical and strategic: Qualitative approaches to the digital humanities. In J. Ridolfo \& W. Hart-Davidson (Eds.), Rhetoric and the digital humanities (pp. 111-126). Chicago, IL: The University of Chicago Press.

Meister, J. C. (2013). Narratology. In The Living Handbook of Narratology. Retrieved from https://bit.ly/2S67eSN

Murray, J. H. (1997). Hamlet on the Holodeck: The Future of Narrative in Cyberspace. Nueva York, NY: The Free Press.

Nisi, V., Oakley, I., \& Haahr, M. (2008). Location-aware multimedia stories: Turning spaces into places. In A. Barbosa (Ed.), Artech 2008. Proceedings of the $4^{\text {th }}$ International Conference on Digital Arts (pp. 72-93), Porto, Portugal: Universidade Católica Portuguesa. Escola das Artes.

Perryman, N. (2008). Doctor Who and the convergence of media: A case study in 'Transmedia Storytelling'. Convergence: The International Journal of Research into New Media Technologies, 14(1), 21-39. doi: https:// doi.org/10.1177/1354856507084417

Pratten, R. (2011). What is transmedia. In Getting Started with Transmedia Storytelling: A practical guide for beginners. [CreateSpace Independent Publishing Platform]. Available in https://bit.ly/2p0QFwG

Riedl, M. O., and Bulitko, V. (2013). Interactive Narrative: An Intelligent Systems Approach. AI Magazine, Spring 2013, 67-77.

Ryan, M-L. (n. d.). Defining Media from the Perspective of Narratology. [Unpublished manuscript], 1-14. Retrieved from https://bit. ly/2QDWOxg 
Ryan, M-L. (2002). Beyond myth and metaphor: Narrative in digital media. Poetics Today, 23(4), 581-609. Retrieved from https://bit.ly/2HhzhOm Ryan, M-L. (2015). Narrative as virtual reality 2. Baltimore, MD: John Hopkins University Press.

Ryan, M-L. (2016). Transmedia narratology and transmedia storytelling. Artnodes, (18), 1-10. Retrieved from https://bit.ly/2LpHi25

Sánchez-Mesa, D., Aarseth, E., Pratten, R., \& Scolari, C. (2016). Transmedia (Storytelling?): A polyphonic critical review. Artnodes, (18), 8-19. Retrieved from https://bit.ly/2EDnCaw

Scolari, C. A. (2009). Transmedia Storytelling: Implicit Consumers, Narrative Worlds, and Branding in Contemporary Media Production. International Journal of Communication, (3), 586-606. Retrieved from https://bit.ly/2SaZ8Zd

Stylianou-Lambert, T. S. (2011). Gazing from home: Cultural tourism and art museums. Annals of Tourism Research, 38(2), 403-421. doi: https:// doi.org/10.1016/j.annals.2010.09.001

Storymap. (2017). Storymap. [Website]. Retrieved from http://storymap.ie/

Swartjes, I., \& Theune M. (2006). A Fabula Model for Emergent Narrative. In S. Gobel, R. Malkewitz, \& I. Iurgel (Eds.), Technologies for Interactive Digital Storytelling and Entertaining: Third International Conference, TIDSE 2006 (pp. 49-60). Berlin - Heidelberg, Germany: Springer-Verlag. Uxdesign. (n. d.). UX Design Defined. [Website]. Retrieved from https://bit.ly/2xBB3T7

Voices of Oakland. (2017). Georgia Tech Augmented Environments Lab. [Webpage]. Retrieved from https://b.gatech.edu/2UX7yoT

Walker, K. (2010). Collective Memory. Research Starters: Sociology (EBSCO). Retrieved from https://bit.ly/2BsJ0Lt [or https://bit.ly/2IwOHP2] Walsh, R. (2011). Emergent Narrative in Interactive Media. Narrative, 19(1), 72-85. doi: 10.1353/nar.2011.0006

Warwick, C. (2012). Studying users in digital humanities. In C. Warwick, M. Terras, \& J. Nythan (Eds.), Digital Humanities in Practice (pp. 1-21). London, England: Facet Publishing. 